\title{
Insurance and Chain Bankruptcy Theory
}

\author{
Bijan Bidabad \\ B.A., M.Sc., Ph.D., Post-Doc. \\ Professor \\ Economics and Chief Islamic Banking Advisor \\ Bank Melli, Iran \\ E-mail:bijan@bidabad.com
}

\begin{abstract}
Purpose: This paper aims to explain the effects of the bankruptcy of one firm in other interrelated companies which are in connection with the bankrupted firm, and shows how the insurance breaks the chain of serial bankruptcy.

Design: By economic analysis of insurance, the "chain bankruptcy" theory is put forward as a new theory.

Findings: Through a mathematical-behavioral model, we will show how insurance breaks the chain bankruptcy in the economy.

Research limitations: We have developed the case with simple modeling based on specific assumptions. In the next step, it would be extended to a more complicated and real set of assumptions.

Practical implications: We show how insurance products can break serial bankruptcy in the economy.

Social implications. It is shown that how insurance stabilizes the economy and make the business cycle oscillation range narrow.

Originality/value: This approach is entirely different and new.
\end{abstract}

Article Type: Research paper

Keywords: Insurance, Bankruptcy, Stabilisation policy, Economic Stabilisation, Business cycles, Economic fluctuations

\section{Introduction}

Economic insurances that are often called commercial insurance have a long history, going back to 6500 years ago. According to a found papyrus belonging to 65 centuries ago, in order to help and protect each other against accidents, ancient Egyptian lithographers used to pay a share to a fund. In 2250 B.C., Hammurabi, king of Babel legislated a law according to which transporters were responsible for the cargo they carried until delivery. In 588-640 B.C., in Greece, there were associations, which established funds and received monthly fees to help and protect members against injury and damages. A similar organization has also been seen in ancient Rome ${ }^{1}$. There are similar cases in the Middle Ages that we will not go through ${ }^{2}$. Modern various ${ }^{3}$ economic insurances can be counted as follows:

- Life insurances

- Personal accidents insurances

- Health insurances

- Insurance for fire accidents and other hazards, such as explosion, theft, earthquake, flood and plane crash

- Cargo insurances

${ }^{\mathrm{I}}$ - Salehi, Jan Ali Mahmoud (2002), Insurance Law, Bimeh Markazi Iran, Training and Publication Office, pp. 65-73.

2 - Before Islam, kinds of insurance have been prevailing in Arabia peninsula. The reason for not being mentioned in narrations may be because The Legislator did not want to go in detail of economic subjects except when necessary.

3 - There are two kinds of insurances called Co-insurance and Re-insurance, which distribute the consequent accident risks subjected to the insurance policy. In co-insurance, two or more insuring companies jointly insure the asset. This kind of insurance is usually used for insuring large risks such as fire accidents or explosions in factories and in case of accident, each insurance company pays his share. Re-insurance is a kind of double insurance, and the first insurer insures the extra risk by another insurer. In other words, the first insurer insures a part of his obligations by another one. Another kind of insurance called Complimentary insurance, which is different from double insurance covers other, or extra risks for the insured. 
- Transportation vehicle (sea, air, road) insurances and its related civic responsibility

- General (civic and professional) responsibility insurance

- All risk insurances for contracting and installations and related civic responsibilities (engineering insurance)

- Operation and cash in till insurances

- Workers honesty insurances

- Oil exploration and excavation and associated industries insurances

- Agricultural products insurances

- Export insurances

In all kinds of above insurances upon the conditions written in their contracts and by taking fees from the insured, the insurer will cover financial support mentioned in their policy, the following general rule is satisfied. Although these contracts are different in details, generally they are similar.

The generality of insurance can be mathematically explained; suppose insurer receives Ai dollars from the $\mathrm{i}^{\text {th }}$ insured to insure asset $\mathrm{B}$. Assume that the probability of losing the asset is equal to P. Accordingly, if the number of insured of this kind of asset is $\mathrm{n}$, and $\mathrm{i}=\mathrm{I} \ldots \mathrm{n}$, the amount received by the insurer will be equal with:

$$
\mathrm{A}=\sum_{\mathrm{i}=1}^{\mathrm{n}} \mathrm{A}_{\mathrm{i}}
$$

The mathematical expectation of the payments of the insurer to insured in case of loss of the assets will be equal to:

$$
\mathrm{B}=\sum_{\mathrm{i}=1}^{\mathrm{n}} \mathrm{P} \mathrm{B}_{\mathrm{i}}=\mathrm{P} \sum_{\mathrm{i}=1}^{\mathrm{n}} \mathrm{B}_{\mathrm{i}}
$$

If the insurance fee is equal to the below ratio:

$$
\mathrm{q}=\frac{\mathrm{A}_{\mathrm{i}}}{\mathrm{B}_{\mathrm{i}}} \quad \mathrm{i}=1, \ldots, \mathrm{n}
$$

By replacing the terms, we can write:

$$
\sum_{i=1}^{n} A_{i}=q \sum_{i=1}^{n} B_{i}
$$

By replacing (I) and (2) in (4), we will have:

$$
\mathrm{A}=\frac{\mathrm{q}}{\mathrm{P}} \mathrm{B}
$$

That is to say, the received amount by the insurer (A) is equal to the ratio of insurance fee $(\mathrm{q})$ to the probability of loss of the asset (P) multiplied by the amount paid to insured (B) by the insurance company. Insurer company profit will be:

$$
\pi_{\mathrm{I}}=\mathrm{A}-\frac{\mathrm{q}}{\mathrm{P}} \mathrm{B}
$$

If $\pi_{\mathrm{I}}=0$, the relation (5) will satisfy and insurer practically will have no profit, which means her economic activity has no yield. Therefore, she should not enter the market. It is the same when $\pi_{\mathrm{I}}<0$, which means his income is less than his payments $\left(\mathrm{A}<\frac{\mathrm{q}}{\mathrm{P}} \mathrm{B}\right)$. So, when 


$$
\pi_{\mathrm{I}}>0 \Rightarrow \mathrm{A}>\frac{\mathrm{q}}{\mathrm{P}} \mathrm{B} \Rightarrow \frac{\mathrm{A}}{\mathrm{B}}>\frac{\mathrm{q}}{\mathrm{P}}
$$

her activity is profitable. In other words, if the probability of an accident is truly estimated, the rate of insurance should be higher than the occurrence of accident probability so that the ratio of income (A) of the insurance company to her cost (B) is larger than one. In this case, the profit rate of the insurance company will be $\frac{\mathrm{q}}{\mathrm{p}}>1$. This analysis means that the insurance company is a commission-receiver agent and by rendering service, obtains a percentage for risk coverage. This action is similar to levying a tax on $\mathrm{n}$ firms to cover their risks. In spite of Reba, insurance acts against economic fluctuations. We can study this phenomenon in business cycle performance. In business cycles, fluctuations caused by seasonal fluctuations and cycles which take 8-II years to finish, turn the economy from recession to crisis and then to recovery and prosperity and again to the recession and a new cycle. Business cycles are a lengthy subject in economics that we do not go into details now.

When the economy is at prosperity stage, total production is at its maximum level and then tends to decline towards recession until finally reach to the crisis. In this process, unemployment of factors of production exacerbates and reaches its peak in crisis. Firms become bankrupt one after another until inventories empty and prices start to rise, and increasing demand increases output and supply and a new recovery, and then prosperity starts in the economy within 8-II years. When the economy is in crisis, by a decrease in prices, producers and intermediates start to bankrupt, and since they cannot keep their financial obligations, social problems will be the consequences of this compulsory cycle in the economy. When the economy reaches its lowest in the crisis stage, prisons will be filled with people who can not afford to pay their debts and obligations. Insurance practically will minimize this cycle and decreases its range. As it is seen in the figure below, the hashed curve has reduced production and income during recovery and prosperity, and instead, has decreased depression and crisis in the next steps. In other words, insurance has reduced the cycle range of short term oscillations and guided the growing trend towards the long-term economic trend, and the economy has been more surrounded.

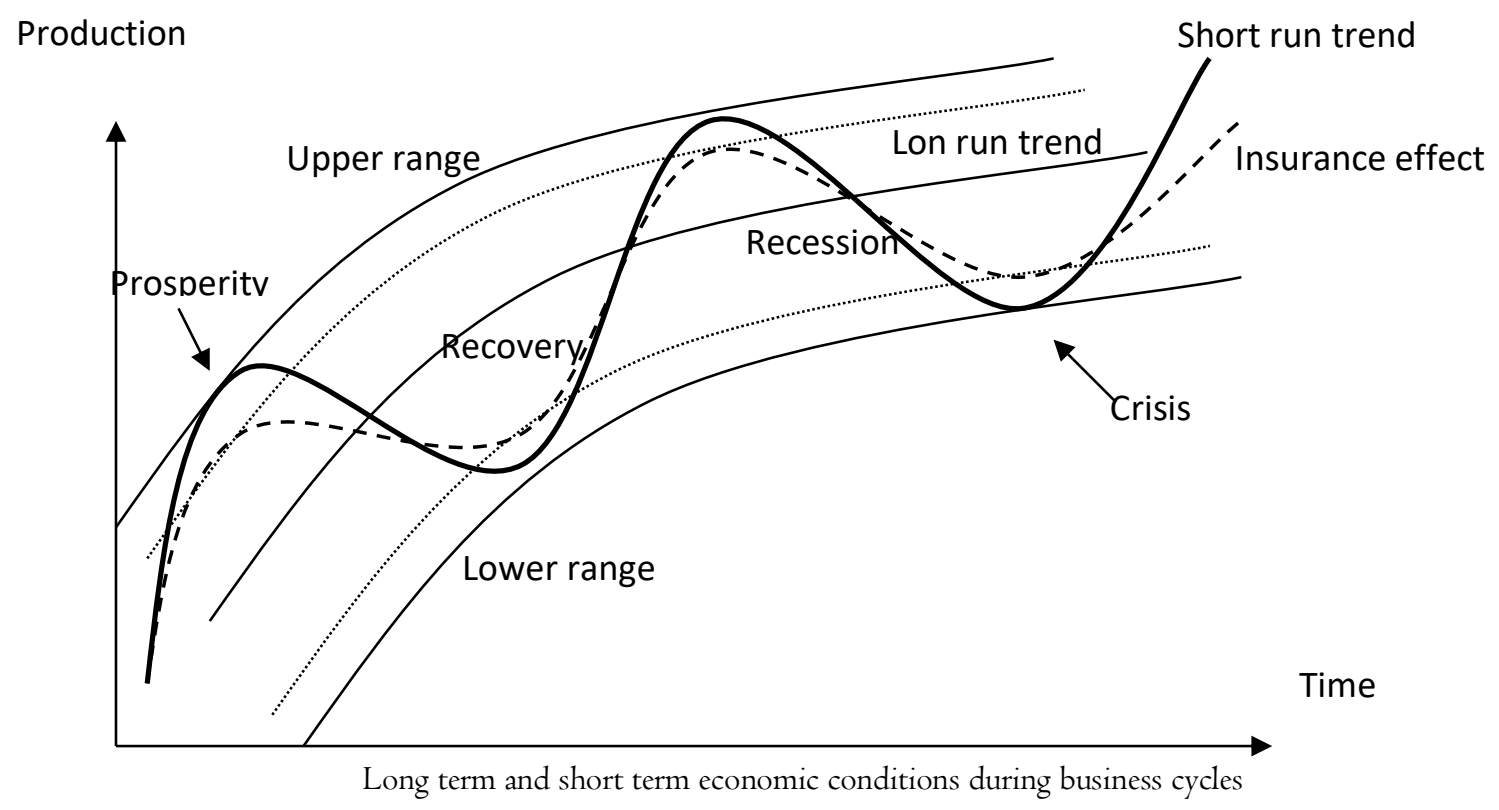

\section{Chain bankruptcy theory}

Let us start a new discussion about chain bankruptcy. Any firm at time t has some assets and liabilities. Its total assets $\left(\mathrm{W}_{\mathrm{i}}\right)$ is equal to the value of all goods and physical capital and other acceptable items in firm's $\left(\mathrm{C}_{i}\right)$ portfolio plus its claims $\left(\mathrm{F}_{i}\right)$ from others. That is: 


$$
\mathrm{W}_{\mathrm{i}}=\mathrm{C}_{\mathrm{i}}+\mathrm{F}_{\mathrm{i}}
$$

On the other side, debts $\left(\mathrm{D}_{\mathrm{i}}\right)$ are equal to the financial obligations of the firm. Altogether, in an economy with $\mathrm{n}$ firms, all claims will be equal to all obligations, or:

$$
\sum_{i=1}^{n} F_{i}=\sum_{i=1}^{n} D_{i}
$$

The net worth (asset) of each firm is equal to:

$$
\mathrm{W}_{\mathrm{i}}^{\mathrm{n}}=\mathrm{C}_{\mathrm{i}}+\mathrm{F}_{\mathrm{i}}-\mathrm{D}_{\mathrm{i}}
$$

By summing up the above equation, and replacing from (9), the inventory in the economy will be equal to the net worth of asset, or,

$$
\sum_{i=1}^{n} W_{i}^{n}=\sum_{i=1}^{n} C_{i}
$$

Now suppose $\mathrm{n}$ firms have transactions with each other and $\mathrm{i}^{\text {th }}$ firm buys $\mathrm{C}_{\mathrm{i}}$ amount of goods from the $\mathrm{i}-\mathrm{I}^{\text {th }}$ firm and sells it to the firm $\mathrm{i}^{+} \mathrm{I}^{\text {th }}$. If this process of purchase is based on credit, it will cause transmission of bankruptcy to other firms. As commodities are sold payable at maturity, $\mathrm{i}^{\text {th }}$ buyer promises to the $\mathrm{i}-\mathrm{I}^{\text {th }}$ seller to pay him the amount of $\mathrm{D}_{\mathrm{i}}$ at maturity. On the other hand, he sells the good to the $\mathrm{i}+\mathrm{I}^{\text {th }}$ buyer and receives a payable written document equal with $\mathrm{F}$, and the commodity goes from firm i-I to firm i and then to firm i+I. These simple sequences will continue several times. To simplify the subject, let us suppose that the face value of the commodity $\mathrm{C}_{i}$ increases $\alpha$ percent in each transaction between firms and these firms have no other assets except this commodity, and all their claims and obligations are related to this commodity, which creates their assets and liabilities. We can design the above chain as follows:

$$
\begin{aligned}
& C_{0}=(1+\alpha) C_{0} \rightarrow C_{1}=(1+\alpha) C_{0} \rightarrow C_{2}=(1+\alpha) C_{1} \rightarrow \ldots C j=(1+\alpha) C_{j-1} \rightarrow \ldots C_{n}=(1+\alpha) C_{n-1} \\
& C_{0} \rightarrow(1+\alpha) C_{0} \rightarrow \quad(1+\alpha)^{2} C_{0} \rightarrow \ldots \quad(1+\alpha)^{j} C_{0} \rightarrow \ldots \quad(1+\alpha)^{n} C_{0} \\
& D_{0}=0 \rightarrow D_{1}=C_{0} \rightarrow D_{2}=C_{1} \rightarrow \ldots D_{i}=C_{i-1} \rightarrow \ldots D_{n}=C_{n-1} \\
& F_{0}=C_{0} \rightarrow F_{1}=(1+\alpha) C_{0} \rightarrow F_{2}=(1+\alpha) C_{1} \rightarrow \ldots . F_{j}=(1+\alpha) C_{j-1} \rightarrow \ldots F_{n}=(1+\alpha) C_{n-1}(12) \\
& \pi_{0}=C_{0} \rightarrow \pi_{1}=\alpha C_{0} \rightarrow \pi_{2}=\alpha C_{1} \ldots \rightarrow \pi_{j}=\alpha C_{j-1} \rightarrow \ldots \pi_{n}=\alpha C_{n-1}
\end{aligned}
$$

The sale of firm zero to firm $\mathrm{n}^{\text {th }}$ has been shown in the first row, and each term indicates the value of the commodity for firm $j$. This process is in the form of difference equation; therefore, the second row by replacing $\mathrm{C}_{i}$ in terms of $\mathrm{C}_{0}$ is essentially the solution for the first row. The third row shows the debt flow of the firms, and the fourth row shows the firms' claims. The fifth row shows the profit of firms zero to firm $\mathrm{n}^{\text {th }}$.

Total profit of the transactions in the economy will be equal to:

$$
\pi=\sum_{\mathrm{i}=0}^{\mathrm{n}} \pi_{\mathrm{i}}=\mathrm{C}_{0}+\sum_{\mathrm{i}=1}^{\mathrm{n}} \alpha(1+\alpha)^{\mathrm{i}-1} \mathrm{C}_{0}=\mathrm{C}_{0}+\alpha \mathrm{C}_{0} \sum_{\mathrm{i}=1}^{\mathrm{n}}(1+\alpha)^{\mathrm{i}-1}
$$

Total debts created in the economy will be: 


$$
\mathrm{D}=\sum_{\mathrm{i}=0}^{\mathrm{n}} \mathrm{D}_{\mathrm{i}}=\sum_{\mathrm{i}=0}^{\mathrm{n}} \mathrm{C}_{\mathrm{i}-1}=\sum_{\mathrm{i}=0}^{\mathrm{n}}(1+\alpha)^{\mathrm{i}-1} \mathrm{C}_{0}=\mathrm{C}_{0} \sum_{\mathrm{i}=0}^{\mathrm{n}}(1+\alpha)^{\mathrm{i}-1}
$$

Total claims set up in the economy will be:

$$
\mathrm{F}=\sum_{\mathrm{i}=0}^{\mathrm{n}} \mathrm{F}_{\mathrm{i}}=\sum_{\mathrm{i}=0}^{\mathrm{n}}(1+\alpha)^{\mathrm{i}} \mathrm{C}_{0}=\mathrm{C}_{0} \sum_{\mathrm{i}=0}^{\mathrm{n}}(1+\alpha)^{\mathrm{i}}
$$

All the above relations have a summation of a geometric progression term:

$$
\sum_{i=0}^{n}(1+\alpha)^{i}=\frac{(1+\alpha)^{n+1}-1}{\alpha}
$$

Therefore, we have:

$$
\begin{aligned}
& \pi=\mathrm{C}_{0}(1+\alpha)^{\mathrm{n}} \\
& \mathrm{D}=\mathrm{C}_{0}\left(\frac{(1+\alpha)^{\mathrm{n}}-1}{\alpha}\right) \\
& \mathrm{F}=\mathrm{C}_{0}\left(\frac{(1+\alpha)^{\mathrm{n}+1}-1}{\alpha}\right)
\end{aligned}
$$

Again, we can find the trueness of the above relations by the below replacement:

$$
\pi=\mathrm{F}-\mathrm{D}
$$

Now suppose that the inventory of the last firm $C_{n}$ is spoiled or damaged because of an accident. Therefore, his claims, which were supposed to be created by selling goods to the next firm and could compensate its debts $\left(D_{n}\right)$ and leave some profit $\pi_{\mathrm{n}}$ for the firm, which is equal to $\alpha(1+\alpha)^{\mathrm{n}-1}$ have been ruined. That is to say, his claim, which is regarded as assets, becomes zero, but his debts and obligations remain. Therefore:

$$
\begin{aligned}
& F_{n}=0 \\
& \pi_{n}=-D_{n}
\end{aligned}
$$

Now its loss is equal to its debts to the firm n-I. The unfulfillment of his financial obligations in equations (I2) will follow a reverse trend; that is equal to $D_{n}$ of claims of the $n-I^{\text {th }}$ firm $\left(F_{n-1}\right)$ is not paid, and the profit of the $n-I^{\text {th }}$ firm is also lost. By using equations (I2), we can write:

$$
F_{n}=(1+\alpha) D_{n}=(1+\alpha)(1+\alpha) C_{n-2}=(1+\alpha) F_{n-1}
$$

Therefore:

$$
\mathrm{F}_{\mathrm{n}-1}=\frac{1}{(1+\alpha)} \mathrm{F}_{\mathrm{n}}
$$


That is to say, the claims of the firm $n-I$ from the firm $n$ have been equal to zero, because of the accident for goods of the $\mathrm{n}^{\text {th }}$ firm. The general form of the above equation applies to all firms:

$$
\mathrm{F}_{\mathrm{i}-1}=\frac{1}{(1+\alpha)} \mathrm{F}_{\mathrm{i}}
$$

Since this equation is recursive, when $\mathrm{F}_{\mathrm{n}}=0$, all $\mathrm{F}_{0}, \ldots, \mathrm{F}_{\mathrm{n}-1}$ will be zero too. That means, in the business of $\mathrm{C}$, all merchants become bankrupt, and since they cannot obtain their claims, they cannot pay their debts. Therefore, all merchants, in relation to this commodity, will be bankrupt. In this case, the losses of all merchants will be:

$$
\pi_{\mathrm{j}}=-\mathrm{D}_{\mathrm{j}}
$$

which can be extracted from equations (I2). The nominal loss to the economy will be:

$$
\sum_{i=0}^{n} \pi_{i}=-\sum_{i=0}^{n} D_{i}=-C_{0}\left(\frac{(1+\alpha)^{n}-1}{\alpha}\right)
$$

\section{Insurance and chain of bankruptcy}

Now suppose in each transaction of commodity C, its owner pays a percentage of it as an insurance fee to the insurance company. If the insurance rate is $\mathrm{q}$ and the $\mathrm{i}^{\text {th }}$ insured always pays $\mathrm{q} \mathrm{C}_{\mathrm{i}}$ to the insurance company, by using equations (I2) we can calculate insurance fees at any time. In the following sequence, $Q_{j}$ is the insurance fee of the $j^{\text {th }}$ insured:

$$
\begin{gathered}
\mathrm{qC}_{0} \rightarrow \mathrm{qC}_{1} \rightarrow \mathrm{qC}_{2} \ldots \rightarrow \mathrm{qC}_{\mathrm{j}} \rightarrow \ldots \mathrm{qC}_{\mathrm{n}} \\
Q_{0}=q C_{0} \rightarrow Q_{1}=q(1+\alpha) C_{0} \rightarrow Q_{2}=q(1+\alpha)^{2} C_{0} \rightarrow \ldots Q_{j}=q(1+\alpha)^{j} C_{0} \rightarrow \ldots Q_{n}=q(1+\alpha)^{n} C_{0}
\end{gathered}
$$

The total insurance fee paid will be:

$$
\mathrm{Q}=\sum_{\mathrm{i}=0}^{\mathrm{n}} \mathrm{Q}_{\mathrm{i}}=\sum_{\mathrm{i}=0}^{\mathrm{n}} \mathrm{qC}_{0}(1+\alpha)^{\mathrm{i}}=\mathrm{qF}
$$

Which means that the total insurance fee paid is equal to the insurance fee rate multiplied by total claims of merchants from each other for transacting commodity C. Assume there is one accident which ruins the commodity in $n$ transactions, so the probability of this accident will be equal to:

$$
\mathrm{P}=\frac{1}{\mathrm{n}}
$$

Therefore, if the commodity is destroyed in the $\mathrm{n}^{\text {th }}$ transaction, the insurance company has to pay $\mathrm{D}_{\mathrm{n}}=\mathrm{C}_{\mathrm{n}-1}$ to the $\mathrm{n}^{\text {th }}$ merchant. The company can afford to pay this amount for her obligations, and since $\mathrm{F}_{\mathrm{n}-1}$ is not zero in this case, the recursive equation (25) for all claims of previous merchants will not become zero, and they obtain their profits. In this case, only the $\mathrm{n}^{\text {th }}$ merchant has no profit, but has even no loss, because the insurance company has covered his loss by paying him $D_{n}$ which is equal to the value of his lost commodity. The insurance company calculates the accident probability through equation (3I) and thereof, insurance fee. In our example, the insurance fee will be: 


$$
\mathrm{q}=\frac{\mathrm{Q}}{\mathrm{F}}
$$

And insurance cost for the jith insured will be $\mathrm{Q}_{\mathrm{j}}=\mathrm{qC}_{0}(1+\alpha)^{\mathrm{j}}$, and therefore, the income of the insurance company will be:

$$
\mathrm{Q}=\mathrm{qC}_{0}\left(\frac{(1+\alpha)^{\mathrm{n}+1}-1}{\alpha}\right)
$$

The mathematical expectation of insurance company cost from equation (3I) will be:

$$
\mathrm{E}(B)=C_{0}\left(\frac{(1+\alpha)^{n+1}-1}{n \alpha}\right)
$$

The mathematical expectation of insurance company profit is as follows:

$$
\mathrm{E}\left(\pi_{I}\right)=Q-B=\left(q-\frac{1}{n}\right) C_{0}\left[\frac{(1+\alpha)^{n+1}-1}{\alpha}\right]
$$

If the insurance fee rate is equal to one divided by the number of transactions, the insurance company profit will be equal to zero, but even in this case, the economy gets rid of bankruptcy. But since the insurance company has offered this service to the community, he has to obtain a profit:

$$
\mathrm{q}=\frac{\mathrm{Q}}{\mathrm{F}}>\frac{1}{\mathrm{n}} \Rightarrow \mathrm{Q}>\frac{\mathrm{F}}{\mathrm{n}}
$$

That means the total insurance fee received by the company should be more than the average claim of one transaction, which is a clear result.

\section{References}

Bidabad, Bijan, (2003) Religious-economic analysis of insurance and characteristics of the Islamic government. Monetary and Banking Research Academy, Central Bank of Iran, 2003. http://www.bidabad.com/doc/bimeh.pdf

Bidabad, Bijan, (2003) Problems of macroeconomic policymaking in Iran, collection of 40 articles by the author, http://www.bidabad.com/doc/ketab-eghtesade-kalan.pdf

Bijan Bidabad, Insurance Products in Rastin Banking, 2014.

http://www.bidabad.com/doc/rastin-insurance-en.pdf

Salehi, Jan Ali Mahmoud (2002), Insurance Law, Bimeh Markazi Iran, Training and Publication Management.

\section{Copyrights}

Copyright for this article is retained by the author(s), with first publication rights granted to the journal. This is an open-access article distributed under the terms and conditions of the Creative Commons Attribution license (http://creativecommons.org/licenses/by/4.0/). 